\title{
La vocación cristiana laical: renovar el mundo con Cristo
}

\section{The Lay Christian Vocation: Renewing the World with Christ}

\section{Vicente BosCH}

Pontificia Università della Santa Croce. Facoltà di Teologia

Roma. Italia

bosch@pusc.it

Resumen: La vocación cristiana laical, en cuanto posibilidad de seguir a Cristo de cerca en medio de las tareas profesionales y sociales, ha sido redescubierta por la eclesiología de comunión elaborada en el Concilio Vaticano II, que concibe la misión de la Iglesia con dos facetas: «anunciar el mensaje de Cristo y su gracia a los hombres» e «impregnar y perfeccionar todo el orden temporal con el espíritu evangélico» (AA n. 5). Por tanto, el trabajo santificado y santificador de los laicos en medio del mundo, para restaurar el orden temporal, tiene un carácter teologal y eclesial, y, en consecuencia, constituye una verdadera vocación, que la pastoral de la Iglesia debe promover, poniendo a Cristo como fundamento y modelo.

Palabras clave: Vocación, Laicos, Misión de la Iglesia.
Abstract: The lay Christian vocation, as a way of following Christ closely in the midst of one's professional and social tasks, has been rediscovered by the ecclesiology of communion elaborated in the Second Vatican Council, which conceives the mission of the Church in its twofold dimension: «to bring the message and grace of Christ to men» and «to penetrate and perfect the temporal order with the spirit of the Gospel» (AA n.5). Therefore, the sanctified and sanctifying work of the laity in the midst of the world, which aims at restoring the temporal order, has a theological and ecclesial character and, consequently, constitutes a true vocation, which the pastoral ministry of the Church must promote by placing Christ as its foundation and model.

Keywords: Vocation, Laity, Mission of the Church. 


\section{INTRODUCCIÓN}

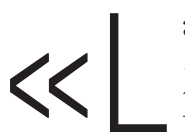

a Iglesia ha decidido interrogarse sobre cómo acompañar a los jóvenes para que reconozcan y acojan la llamada al amor y a la vida en plenitud» ${ }^{1}$. Esta declaración de intenciones, que motiva la convocatoria de la XV Asamblea General Ordinaria del Sínodo de Obispos, requiere, para ser puesta en práctica, una adecuada comprensión del concepto «vocación», que incluya una visión global de todas sus concreciones. Puesto que «la vocación al amor asume para cada uno una forma concreta en la vida cotidiana a través de una serie de opciones que articulan estado de vida (matrimonio, ministerio ordenado, vida consagrada, etc.), profesión, modalidad de compromiso social y político, estilo de vida, gestión del tiempo y del dinero, etc. ${ }^{2}$, es más que oportuno reflexionar sobre la llamada al amor recibida, acogida y vivida en la condición secular, en el ejercicio de una profesión civil que busca dar gloria a Dios y servir a los demás. Con mayor motivo si se tiene en cuenta que la condición laical es la predominante en el Pueblo de Dios, y que su vivencia con sentido vocacional es todavía poco frecuente, a pesar de los cincuenta años transcurridos desde el Concilio Vaticano II.

La teología y el Magisterio del siglo XX han profundizado y expuesto una concepción cristiana del trabajo rica y atrayente, que tiene su zenit en la clara afirmación wojtyliana de la preeminencia del sentido subjetivo del trabajo -perfeccionamiento personal de quien lo realiza- sobre el sentido objetivo o de producción de cambios en la naturaleza ${ }^{3}$; y en la propuesta de una «espiritualidad del trabajo» en el capítulo quinto de la encíclica Laborem exercens (14-IX-1981). En el recorrido que ahora iniciamos conviene tener ante nuestros ojos algunas de las más importantes ideas sobre la visión cristiana del trabajo: primero, su inclusión en el plan eterno de Dios para que el hombre con-

${ }^{1}$ SínOdo de los OBISPOS, Los jóvenes, la fe y el discernimiento vocacional. Documento preparatorio. Introducción, Città del Vaticano: Libreria Editrice Vaticana, 2017, 5.

2 Ibid., 6.

3 SAN Juan Pablo II, enc. Laborem exercens, n. 6: «Como persona, el hombre es pues sujeto del trabajo. Como persona él trabaja, realiza varias acciones pertenecientes al proceso del trabajo; éstas, independientemente de su contenido objetivo, han de servir todas ellas a la realización de su humanidad, al perfeccionamiento de esa vocación de persona, que tiene en virtud de su misma humanidad. (...) El fundamento para determinar el valor del trabajo humano no es en primer lugar el tipo de trabajo que se realiza, sino el hecho de que quien lo ejecuta es una persona. Las fuentes de la dignidad del trabajo deben buscarse principalmente no en su dimensión objetiva, sino en su dimensión subjetiva». 
tinúe y perfeccione la Creación ${ }^{4}$; después, que mediante su actividad laboral el hombre se perfecciona ${ }^{5}$; y finalmente, que el trabajo es medio de unión con Dios, ocasión de darle gloria, e instrumento de santificación propia y ajena ${ }^{6}$.

El trabajo se presenta, por tanto, como vocación natural del hombre y remite a toda actividad humana -intelectual y/o corporal- que modifica y transforma el mundo, dando lugar al progreso y al desarrollo del que gozarán también las sucesivas generaciones. Expresa el dominio del hombre sobre la naturaleza. Y como el destino del mundo está vinculado al del hombre, ese progreso, tiene mucho que ver con el Reino de Dios, aunque no se identifique con él ${ }^{7}$. La constitución conciliar Gaudium et spes recuerda que «la razón más alta de la dignidad humana consiste en la vocación del hombre a la unión con Dios» (n. 19). En este sentido, toda actividad humana debe tender hacia esa meta, hacia la plena realización de la vocación; y, por voluntad divina, el trabajo constituye un modo concreto y adecuado para que el hombre realice su vocación a la comunión con la Santísima Trinidad. Evidentemente, esto no debe conducir a excluir de la vocación laical a quien no pueda desarrollar un trabajo profesional, por ejemplo, por enfermedad. En este caso, su «trabajo» consiste en unirse a los sufrimientos de Cristo en la Cruz, contribuyendo así, quizá con una mayor eficacia, a la renovación del mundo.

\section{VOCACIÓN BAUTISMAL Y VOCACIONES PECULIARES}

Se afirma con cierta reiteración que frente a una pastoral y praxis vocacional muy variada y detallada, encontramos, sin embargo, una teología vo-

${ }^{4}$ Concilio Vaticano II, const. Gaudium et spes, n. 34/b: «[Los hombres y mujeres] con razón pueden pensar que con su trabajo desarrollan la obra del Creador, sirven al bien de sus hermanos y contribuyen de modo personal a que se cumplan los designios de Dios en la historia».

5 Ibid., n. 35/a: «La actividad humana, así como procede del hombre, así también se ordena al hombre. Pues éste con su acción no sólo transforma las cosas y la sociedad, sino que se perfecciona a sí mismo».

${ }^{6}$ IDEM, const. Lumen gentium, n. 41/e: «Aquellos que están dedicados a trabajos muchas veces fatigosos deben encontrar en esas ocupaciones humanas su propio perfeccionamiento, el medio de ayudar a sus conciudadanos y de contribuir a elevar el nivel de la sociedad entera y de la creación. Pero también es necesario que imiten en su activa caridad a Cristo, cuyas manos se ejercitaron en los trabajos manuales y que continúan trabajando en unión con el Padre para la salvación de todos. Gozosos en la esperanza, ayudándose unos a otros a llevar sus cargas, asciendan mediante su mismo trabajo diario, a una más alta santidad, incluso con proyección apostólica».

${ }^{7}$ IDEM, const. Gaudium et spes, n. 39/b: «Por ello, aunque hay que distinguir el progreso terreno del crecimiento del Reino de Cristo, sin embargo, el primero, en la medida en que puede contribuir a ordenar mejor la sociedad humana, interesa mucho al Reino de Dios». 
cacional débil o todavía en construcción ${ }^{8}$. Efectivamente, mientras son abundantes los estudios bíblicos y de espiritualidad sobre la vocación, se echa en falta la aportación de la dogmática, en especial de la cristología. El cristocentrismo vocacional o una cristología de la vocación ayudaría, ciertamente, a renovar una pastoral vocacional capaz de afrontar una juventud secularizada y frágil en sus estructuras psicológicas (estas páginas procurarán adoptar un planteamiento cristológico). Pero, a pesar de esas carencias denunciadas y de la conveniencia de una profundización teológica, se debería reconocer que el concepto de vocación transmitido por el Concilio Vaticano II es rico en sus diversas dimensiones antropológica, teocéntrica, eclesiológica, y espiritual ${ }^{9}$. Para captar el calado de esta afirmación conviene realizar un breve recorrido histórico acerca de la variación sufrida por el concepto «vocación», y mostrar su articulación interna: «bautismal», «personal-particular»y «peculiar-específica».

\section{a) Desde una interpretación restringida a una noción amplia y renovada}

En la época post-apostólica y de persecución, los primeros cristianos eran conscientes de que el seguimiento de Cristo respondía a una llamada. Para referirse a ellos, san Pablo emplea con frecuencia el término «los llamados» (Rom 1,6; 8,28; 1 Cor 1,2; 1,9; 1,24): los destinatarios de sus cartas eran hombres y mujeres objeto de vocación y sujetos con vocación. La vocación cristiana introducía en el ámbito de la santidad de Dios y capacitaba para vivir una conducta santa. En este sentido, las cartas paulinas parecen estructuradas en dos partes: la primera indica «has resucitado con Cristo», «eres una nueva criatura»; y la segunda impera «vive como una nueva criatura», «vive como un resucitado». Un estudio de los diversos textos paulinos sobre la vocación llegaba a la siguiente conclusión: «un primer resultado del examen del vocabulario vocacional es la universalidad cristiana de la vocación divina -no hay ningún fiel cristiano que no la haya recibido- hasta el punto que cristiano y llamado se equivalen ${ }^{10}$.

${ }^{8}$ Cfr. Rocchetta, C., «Forti e costanti ispirazioni di fede. Teologia della vocazione. Valutazione e fondamento cristologico», Seminarium 36 (1996) 35; RocheTTA, C., «Quale teologia al centro dell'animazione e della pastorale vocazionale?», Vocazioni 23 (2006/4) 4.

$9 \mathrm{Al}$ respecto, se puede consultar Bosch, V., «Vocación», en IZquierdo, C. (dir.), Burgrgraf, J., Arocena, F. M. y Brugarolas, M., Diccionario de Teología, 3 ed. Pamplona: Eunsa, 2014, 10571067.

10 Miralles, A., «La vocación de los cristianos: reflexión teológica sobre los principales textos neotestamentarios», en Villar, J. R. (ed.), Communio et sacramentum, Pamplona: Eunsa, 2003, 364. 
Las vicisitudes posteriores hicieron perder poco a poco el sentido vocacional que animaba la conciencia y la vida de los primeros cristianos: la paz de Constantino comportó un debilitamiento de la vida cristiana -el aumento de conversiones no garantizaba la calidad-; la aparición del monaquismo hizo deslizar el originario sentido de vocación hacia un significado subjetivo de llamada a seguir a Cristo en una forma de vida que se consideraba perfecta; finalmente, la fuerte tendencia medieval a estructurar jerárquicamente la sociedad favoreció una división entre los clérigos -destinatarios de una llamada exterior (elección eclesial) a realizar las funciones del culto-, los monjes -receptores de una llamada interior (carisma) a un radical seguimiento-, y los laicos que, como simples miembros del pueblo, no serían objeto de ninguna llamada ${ }^{11}$. Posteriormente, la época Moderna trajo consigo el humanismo cristiano y la reforma protestante que, además de favorecer una tendencia a la interioridad y al subjetivismo, se abrían a una valoración de todos los estados -incluyendo las profesiones laicales- como vías de concreción de la vocación cristiana de todos los bautizados. Esa bocanada de aire fresco duró poco: el error luterano que prácticamente identificaba el sacerdocio común de todos los fieles con el sacerdocio ministerial produjo la lógica reacción de Trento y de la teología católica, que subrayaba la grandeza del sacerdocio ministerial y desviaba su atención del sacerdocio común de todos los fieles. Así, a partir del s. XVIII, también se aplicará al sacerdocio ministerial el término «vocación» con el significado de llamada interior procedente de Dios, propia, hasta entonces, de los religiosos. De modo que llegamos al siglo XX, en el que el lenguaje -tanto eclesial como corriente- indica con el término «vocación» la llamada a la vida religiosa y al sacerdocio.

El Concilio Vaticano II ampliará horizontes y enriquecerá la noción de vocación. La llamada universal a la santidad convoca a todos los hombres a una vida divina en Cristo. Acoger esa llamada universal a la santidad constituye el ser cristiano y comporta una vocación: la cristiana o bautismal. Y Dios mismo es quien, después, toma la iniciativa para colocar a cada cristiano dentro de su plan de salvación. La vocación se entiende, por tanto, como «realidad universal, que tiene su fundamento en la voluntad salvífica de Dios (...) [y la vez incluye] el designio particular, singular e irrepetible de Dios para cada hombre, que es expresión de su amor y que constituye, desde el punto di vista del hom-

${ }^{11}$ Cfr. Bosch, V., «Vocación», en Diccionario de Teología, 1060; Lefeuvre, G., «Vocation», Catholicisme 15 (2000) 1257. 
bre, la luz que ilumina el sentido de su existencia, situándole de un modo concreto en y ante la Iglesia y el mundo» ${ }^{12}$. En este sentido, la vocación cristiana, bautismal, precede y otorga sentido a las diversas especificaciones, expresiones y modos de responder a la llamada. Es decir, la doctrina conciliar, sin abandonar su solicitud por las vocaciones sacerdotales y a la vida religiosa -a las que dedicó tres decretos-, las encuadra dentro de la común y fundamental vocación cristiana, que es vocación a una misma santidad -la de Cristo-, sin rebajas que permitan ahora alcanzarla a quienes antes no podían, ni propuesta de dos niveles de santidad ${ }^{13}$. Ante la iniciativa divina que incluye a cada cristiano en el plan de salvación, el bautizado toma conciencia de esa llamada y acoge la propuesta divina personalizada, desarrollándola en el tiempo y de acuerdo a los dones recibidos - tanto de naturaleza como sobrenaturales- y circunstancias personales ${ }^{14}$. Conviene señalar que la universalidad de la llamada a la santidad no sólo es subjetiva -referida a todos los hombres-, sino también objetiva, en el sentido de que todos los estados y circunstancias de la vida pueden ser lugar y medio de santificación ${ }^{15}$. Si la santidad se vive «a través de todo eso»-es decir, desde y mediante los distintos estados y circunstancias de la vida-, entonces la santidad, además de ser multiforme, no es un ideal abstracto, sino realidad concreta y asequible.

12 Álvarez de las Asturias, N., «Teología y pastoral de la vocación en el contexto actual», Scripta Theologica 49 (2017) 596.

13 Concilio VatiCANo II, const. Lumen gentium, n. 11/c: «Todos los fieles cristianos, de cualquier condición y estado, fortalecidos con tantos y tan poderosos medios de salvación, son llamados por el Señor, cada uno por su camino, a la perfección de aquella santidad con la que es perfecto el mismo Padre»; ibid., n. 32/b: «Es común la dignidad de los miembros, que deriva de su regeneración en Cristo; común la gracia de la filiación; común la llamada a la perfección: una sola salvación, única la esperanza e indivisa la caridad». [...].

${ }^{14}$ Es oportuno aclarar que, en sentido pleno, la vocación sólo se da con la respuesta libre del hombre, y esa respuesta «pasa necesariamente por crear las condiciones para que la vocación pueda entenderse en términos de libertad. Libertad, en primer lugar, de cualquier coacción externa. Pero, sobre todo, de libertad como capacidad de elección y, más radicalmente aún, como capacidad de autodeterminación y de adhesión» (ÁLVAREZ DE LAS ASTURIAS, N., Teología y pastoral de la vocación, 598).

15 El n. 41 de Lumen gentium dedica tres largos párrafos a reseñar distintos géneros de vida, situaciones particulares o categorías de fieles -obispos, presbíteros diáconos, esposos y padres, viudos y solteros, trabajadores y enfermos- que configuran diversos modos de santificación, concluyendo con estas palabras: «Por tanto, todos los fieles cristianos, en las condiciones, ocupaciones o circunstancias de su vida, y a través de todo eso, se santificarán más cada día si lo aceptan todo con fe de la mano del Padre celestial y colaboran con la voluntad divina, haciendo manifiesta a todos, incluso en su dedicación a las tareas temporales, la caridad con que Dios amó al mundo». La cursiva es nuestra. 


\section{b) La llamada y sus especificaciones}

La llamada a la bienaventuranza, a la unión eterna con Dios, es siempre en Cristo y a través de Cristo. Lo expresa perfectamente san Pablo en Ef 1,4: «ya que en él [Jesucristo] nos eligió antes de la creación del mundo para que fuéramos santos y sin mancha en su presencia, por el amor». Por tanto, el fundamento y la fuente de toda identidad vocacional está en el plan creador de Dios que imprime en el hombre la imagen del Hijo y, con ella, la capacidad de conocer y amar la voluntad de Dios. Después de las vocaciones narradas en los Evangelios, Jesús continúa saliendo al encuentro de los hombres y mujeres y a cada uno le dice «sígueme». El encuentro con Cristo, que en el Bautismo hace pasar de la muerte a la Vida, ha de considerarse como el momento en el que el plan divino, antes mencionado, contacta con la historia y funda en el tiempo la identidad vocacional. Ser consciente de ese encuentro no es algo automático ni puede darse por descontado: la experiencia demuestra que ello requiere algún acontecimiento -como el de Saulo en el camino de Damascoo una progresiva familiaridad con Cristo ${ }^{16}$. Sólo a partir de la conciencia de saberse llamado por Cristo a colaborar con Él en la implantación del Reino de Dios -y de una respuesta o actitud afirmativa- se puede hablar de vocación «bautismal» o cristiana. Toda vocación cristiana es, por tanto, una historia de amor con Cristo, que lleva a concebir la propia vida como un don que ha de ser re-donado. Más aún, la identificación con Cristo, el ser alter Christus, ispe Christus ${ }^{17}$, que llevó a cabo su misión redentora con su donación total, constituye la plenitud del hombre, su perfección: para él es lo más «naturalsobrenatural», por haber sido creado para ser santo.

A la conocida afirmación de que el cristianismo es un encuentro con la Persona de Cristo, conviene añadir que tal encuentro tiene lugar en lo más profundo del ser, allí donde reside el deseo de amar y ser amado de toda persona, particularmente vivo en la edad juvenil. El contexto actual requiere que

${ }^{16}$ SAN JuAn Pablo II, enc. Redemptor hominis, n. 10: «El hombre que quiere comprenderse hasta el fondo a sí mismo, [...] debe, con su inquietud, incertidumbre e incluso con su debilidad y pecaminosidad, con su vida y con su muerte, acercarse a Cristo. Debe, por decirlo así, entrar en Él con todo su ser, debe "apropiarse" y asimilar toda la realidad de la Encarnación y de la Redención para encontrarse a sí mismo».

17 Así le gustaba a san Josemaría definir al cristiano. Cfr. ARANDA, A., «El cristiano, Alter Christus, ipse Christus en el pensamiento del beato Josemaría Escrivá de Balaguer», en BELDA, B., EsCUDero, J., Illanes, J. L. y O'Callaghan, P. (ed.), Santidad y mundo. Actas del Simposio teológico de estudio en torno a las enseñanzas del beato fosemaría Escrivá, Pamplona: Eunsa, 1996, 129-187. 
el mensaje cristiano sea capaz de atraer y fascinar a los jóvenes en esta exigencia antropológica que Cristo satisface ampliamente («porque nos has hecho para ti y nuestro corazón está inquieto hasta que descanse en ti») ${ }^{18}$.

Los Evangelios nos transmiten que ser discípulo de Cristo es exigente: Él pide todo y para siempre. Ante Cristo, que pasa y llama, la libertad del hombre es interpelada a una respuesta rápida, total y definitiva, sin medias tintas, pactos ni atajos. Reconocer a Cristo como Mesías e Hijo de Dios implica acoger su mensaje y seguirlo hasta la Cruz: se es verdaderamente libre cuando se es capaz de asumir con amor la propia vida y hacer de ella un don para los demás, como Cristo en la Cruz. Esta actitud del cristiano otorga sentido a la propia historia, sustrayéndole del posible vacío existencial y de una aparente inutilidad. Por otra parte, siendo Cristo el Alfa y la Omega, el principio y fin de todas las cosas, Él constituye la clave de interpretación de todo el acontecer de los hombres. Y el bautizado que responde a la llamada de Cristo se convierte en colaborador de esa misión redentora, y detentor de una visión del mundo y de la historia que revela su sentido último. Por eso, toda vocación implica una misión, una tarea que cumplir en el plan providente de Dios. Como ha señalado el documento preparatorio del Sínodo,

«Acoger la misión implica la disponibilidad de arriesgar la propia vida y recorrer la vía de la Cruz, siguiendo las huellas de Jesús, que con decisión se puso en camino hacia Jerusalén (cfr. Lc 9,51) para ofrecer su vida por la humanidad. Sólo si la persona renuncia a ocupar el centro de la escena con sus necesidades se abre el espacio para acoger el proyecto de Dios a la vida familiar, al ministerio ordenado o a la vida consagrada, así como para llevar a cabo con rigor su profesión y buscar sinceramente el bien común» ${ }^{19}$.

Esa tarea que Cristo asigna a cada persona se va descubriendo en diálogo con Él y con la propia historia, teniendo muy en cuenta los propios talentos naturales, los dones sobrenaturales, las personales inclinaciones y el carácter, que han de considerarse elementos constitutivos de la propia vocación. En este sentido, conviene subrayar la implícita invitación del texto recientemente citado a considerar la «vocación» profesional como parte de la «vocación» sobrenatural.

18 San Agustín, Confesiones I, 1, 1, 8 ed. Madrid: BAC, 1991, 73.

19 SínODO DE LOS OBISPOS, Los jóvenes, la fe y el discernimiento vocacional, 43. 
A partir de la premisa de la universalidad de la llamada, tanto de su carácter colectivo -que no significa algo genérico o indeterminado (hay elección de un Pueblo, formación de un Cuerpo, y destino común)- como también individual ${ }^{20}$, la vocación se declina y especifica en cada bautizado que es consciente de ser llamado por Dios para una misión en la Iglesia. Es decir, la vocación cristiana alcanza a cada uno de modo personalizado: «Dios no deja a ningún alma abandonada a un destino ciego: para todas tiene un designio, a todas las llama con una vocación personalísima, intransferible» ${ }^{21}$. El modo en el que el bautizado toma conciencia de la llamada pertenece al misterio de la relación entre Dios y el alma, pero siempre se da la mediación humana para entender la Palabra que Dios dirige a cada uno en el ámbito de la Iglesia, en el espacio querido por Dios para su encuentro con los hombres. Existe, por tanto, una dimensión eclesial en toda vocación. En cualquier caso, estamos ya ante la vocación «personal» o particular, concreción para cada uno de la vocación general cristiana o bautismal, que siempre comporta participar en la tarea salvífica de la Iglesia de modo único e irrepetible, en el matrimonio o en el celibato, desde la juventud o a partir de la madurez e, incluso, de la vejez.

Una de las posibles formas de concreción de la llamada a la santidad en la vocación personal o particular tiene lugar cuando el cristiano es situado ante una convocatoria peculiar, ante un proyecto divino que le precede, un modo concreto de vivir el espíritu de Cristo, una misión peculiar que implica un compromiso específico (por ejemplo, la vocación sacerdotal). Éstas son las llamadas vocaciones «peculiares», habitualmente injertadas en un carisma y una institución; es decir, las que en el pasado se identificaban con el antiguo concepto de vocación -sacerdocio y vida religiosa-, pero hoy también ampliadas a nuevas formas de vida laical y abiertas a futuras nuevas determinaciones. Estas vocaciones peculiares comportan un determinado estilo de vida cristiana, un modo concreto de realizar el mensaje del Evangelio, una propia espiritualidad, una peculiar tarea dentro de la única misión de la Iglesia. Su dimensión institucional entraña el seguimiento de un camino ya abierto en la Iglesia, a cuya autoridad compete reconocer su autenticidad cristiana y eclesial. Importa aclarar, sin embargo, que «constituiría un error pensar que la persona cuya vocación personal es la concreción de una vocación específica (en el sentido

${ }^{20}$ Cfr. LÉSAGE, S., «Vocation, I. Écriture sainte», DSp 16 (1994) 1082-1092.

21 SAn Josemaría Escrivá, Conversaciones con Mons. Escrivá de Balaguer, n. 106/a, ed. crítico-histórica preparada por ILlanEs, J. L. y MÉNDIZ, A., Madrid: Rialp, 2012, 454. 
indicado), se encuentre más llamada a la comunión con Dios y a la edificación de la Iglesia que aquellos cuya vocación personal es, por decirlo así, concreción directa de la común vocación cristiana» ${ }^{22}$. Por tanto, y para concluir, la vocación bautismal al seguimiento de Cristo se declina personalmente: en algunos casos como vocación peculiar, pero en la mayoría como simple determinación de la vocación cristiana, en sus múltiples circunstancias de talentos, tendencias, estado, tiempo y lugar. En ambas posibilidades -en una vocación peculiar o fuera de ella- se puede inscribir la vocación laical, la vivencia del seguimiento de Cristo en el ámbito secular de las estructuras del mundo, tanto en el matrimonio como en el celibato apostólico.

\section{LA SANTIFICACIÓN DEL MUNDO, MISIÓN DE TODA LA IGLESIA}

\section{a) El Verbo Encarnado restaura las cosas creadas}

La Iglesia, en cuanto continuadora de la misión de Cristo, transmite la gracia que mana de la Cruz redentora, purificando las almas y también la Creación, todas heridas por el pecado. Una de las consecuencias de esa primera desobediencia, señaladas en el capítulo tercero del Génesis, es que el mundo se vuelve hostil al hombre ${ }^{23}$. Esa quiebra entre las cosas creadas -originalmente buenas, pues salieron de las manos del Creador- y el hombre, es sanada por la gracia, cuando el bautizado utiliza las realidades terrenas como medio para llegar a Dios y -en el respeto de la naturaleza y las leyes de las cosas-, mediante su actividad laboral, las ofrece a Dios como culto espiritual: «la espera ansiosa de la creación anhela la manifestación de los hijos de Dios. Porque la creación se ve sujeta a vanidad, no por su voluntad, sino por quien la sometió, con la esperanza de que también la misma creación será liberada de la esclavitud de la corrupción, para participar de la libertad gloriosa de los hijos de Dios» (Rom 8,19-21). Cristo en su andar terreno inició la gran tarea de purificación y renovación de las cosas creadas: trabajó por casi veinte años -tiempo también

22 OcÁrIz, F., «Vocación a la santidad en Cristo y en la Iglesia», en BELdA, M., Escudero, J., Illanes, J. L. y O'Callaghan, P. (ed.), Santidad y mundo, Pamplona: Eunsa, 1996, 51.

${ }^{23}$ Gn 3,17-19: «Maldita sea la tierra por tu causa. Con fatiga comerás de ella todos los días de tu vida. Te producirá espinas y zarzas, y comerás las plantas del campo. Con el sudor de tu frente comerás el pan, hasta que vuelvas a la tierra». SAN JUAN PABLO II, ex. ap. Reconciliatio et paenitentia, n. 15: «Desgarrado de esta forma [por el pecado] el hombre provoca casi inevitablemente una ruptura en sus relaciones con los otros hombres y con el mundo creado». 
redentor- en un modesto oficio, dominando y perfeccionando la materia prima; las incontables curaciones milagrosas que nos narran los Evangelios sanaban concretas imperfecciones de la naturaleza; en Caná, las tinajas de agua no se convierten en un vino normal o mediocre, sino de gran calidad; y, por último, Cristo en la Cruz constituye el paradigma de la secularidad, entendida como voluntaria inmersión en el mundo para renovarlo y llevarlo hacia Dios. No extraña, por tanto, que cuando el beato Pablo VI habló por vez primera de «secularidad de la Iglesia», en cuanto responsabilidad del Pueblo de Dios ante el mundo creado, señalara que esta dimensión secular «hunde su raíz en el misterio del Verbo Encarnado» ${ }^{24}$. La afirmación del Papa Montini tiene su precedente en un texto conciliar de amplias perspectivas y consecuencias: «La obra de la redención de Cristo, que de suyo tiende a salvar a los hombres, comprende también la restauración incluso de todo el orden temporal. Por tanto, la misión de la Iglesia no es sólo anunciar el mensaje de Cristo y su gracia a los hombres, sino también el impregnar y perfeccionar todo el orden temporal con el espíritu evangélico» ${ }^{25}$. Se trata de una moneda con dos caras: una es la salvación de las almas; la otra, la santificación del mundo. Esta última consiste en purificar y renovar el mundo, conducirlo hacia Dios. Y todos en el Pueblo de Dios -sacerdotes, religiosos y laicos- participan en esa responsabilidad y misión.

\section{b) Los cristianos y su responsabilidad de restaurar el orden temporal}

La modalidad de participación en esa responsabilidad de llevar el mundo hacia Dios será diversa según los estado de vida y vocaciones ${ }^{26}$ : los sacerdotes, con su ministerio, hacen presente en el mundo la gracia de Cristo; los religiosos reflejan en el mundo actual el modo de vida del mundo futuro, subrayando así la vocación eterna del hombre; y a los laicos, en virtud de su carácter secular, «corresponde, por propia vocación, tratar de obtener el reino de Dios gestionando los asuntos temporales y ordenándolos según Dios. Viven en el si-

24 Beato Pablo VI, Discurso a los representantes de los institutos seculares sacerdotales y laicales, 2-II1972.

25 Concilio Vaticano II, decr. Apostolicam actuositatem, n. 5.

26 San Juan Pablo II, ex. ap. Christifideles laici, n. 55: «Todos los estados de vida, [...], están al servicio del crecimiento de la Iglesia; son modalidades distintas que se unifican profundamente en el "misterio de comunión” de la Iglesia y que se coordinan dinámicamente en su única misión». La cursiva es nuestra. 
glo, [... y ] Allí están llamados por Dios, para que, desempeñando su propia profesión guiados por el espíritu evangélico, contribuyan a la santificación del mundo como desde dentro, a modo de fermento» ${ }^{27}$. No debe pasar desapercibido el lenguaje «vocacional» utilizado por Lumen gentium para referirse a los laicos: «corresponde, por propia vocación», «allí están llamados por Dios». La ordenación a la gloria de Dios de las realidades terrenas es -decíamos- tarea de todos en la Iglesia, y en ella se participa con modalidades diversas y complementarias. Sin embargo, hay que reconocer que la modalidad laical tiene una particular relevancia: «en el cumplimiento de este deber universal corresponde a los laicos el lugar más destacado. Por ello, con su competencia en los asuntos profanos y con su actividad elevada desde dentro por la gracia de Cristo, contribuyan eficazmente a que los bienes creados, de acuerdo con el designio del Creador y la iluminación de su Verbo, sean promovidos, mediante el trabajo humano, la técnica y la cultura civil, para utilidad de todos los hombres sin excepción ${ }^{28}$. Una reciente valoración de la novedad de las enseñanzas del decreto conciliar sobre el apostolados de los laicos, Apostolicam actuositatem, en su quincuagésimo aniversario, señalaba logros y límites: «El apostolado visto como patrimonio de toda la Iglesia; la vocación de cada cristiano al apostolado, proveniente de su simple condición de bautizado; la específica función laical y eclesial de impregnar con el Evangelio las realidades temporales; y una auténtica espiritualidad laical que una armónicamente vocación y misión, formaban un prometedor cuadro global, que quizás los posteriores desarrollos no han explorado todavía hasta el fondo esos caminos» ${ }^{29}$.

De la eclesiología de comunión propuesta por el Concilio se deriva que todos los cristianos son responsables de la misión de la Iglesia, que consiste en la salvación de las almas y la santificación del mundo. Es decir, a todos los miembros de la Iglesia compete -aunque en modos diversos- participar en esa única misión: no «en una parte» de la misión. Quedaron atrás los años en los que se pensaba que el edificio de la Iglesia constaba de dos pisos: en la planta terrena o principal los sacerdotes y religiosos se ocupaban de lo sacro (la salvación de las almas); y en el primer piso, los laicos se dedicaban a lo profano (el mundo). Los laicos concurren a llevar a cabo «toda» la misión de la Iglesia

27 Concilio Vaticano II, const. Lumen gentium, n. 31/b.

${ }^{28} \mathrm{Ibid} .$, n. 36/b.

29 GOYRET, P., «The Decree Apostolicam actuositatem, Highlights of Vatican II's Teaching on Laity», Annales theologici 31 (2017) 102. La traducción es nuestra. 
en virtud del sacerdocio común de los fieles, que les hace partícipes de la triple función mesiánica de Cristo: con la función profética transmiten el Evangelio en su ambiente (familiar, laboral, social); con la función sacerdotal hacen de ellos mismos y de sus actividades -principalmente el trabajo- un sacrificio espiritual, aceptable a Dios por Jesucristo (cfr. 1 Pe 2,5); y, por último, con la función real participan en la instauración del Reino, es decir, someten al Reino las estructuras temporales informándolas con la caridad. En este sentido, la función real está particularmente relacionada con esa santificación del mundo, también presente en la función sacerdotal. Como señalé recientemente, «la participación de los laicos en las tres funciones mesiánicas de Cristo muestran con suficiente claridad que el horizonte de compromiso cristiano propio de los laicos excede, en mucho, a una posible y oportuna participación o colaboración en las funciones propias del clero» ${ }^{30}$.

La eclesialidad de la misión santificadora del mundo que realizan los laicos no parece haber sido suficientemente reconocida y profundizada. «No se ha desarrollado una conveniente reflexión sobre la nítida observación de Christifideles laici [n. 15]: "el ser y el actuar en el mundo son para los fieles laicos no sólo una realidad antropológica y sociológica, sino también, y específicamente, una realidad teológica y eclesial" ${ }^{31}$. Con algo de superficialidad se ha tendido a distribuir la vocación y misión del laico en «la Iglesia y en el mundo» en dos ámbitos paralelos, aplicando un dualismo en el ser y actuar del laico, que alternativamente intervendría o en la Iglesia o en el mundo, como si fueran realidades opuestas o en insanable antinomia. Una cierta inercia de la literatura teológica y pastoral ha llevado a identificar la misión del laico en la Iglesia con el ejercicio de los ministerios laicales y con su responsable y necesaria participación en las estructuras organizativas y administrativas eclesiásticas, dejando en el olvido su actuación en el mundo, como si ésta se desarrollara en la periferia de la vida de la Iglesia. El corazón de la vida de la Iglesia no puede limitarse a la liturgia y a la catequesis (la salvación de las almas), sin dejar espacio al cumplimiento de la misión de renovar el mundo y conducirlo hacia Dios. Del mismo modo que no se duda de la eclesialidad del ejercicio del diaconado permanente, ni de la función catequética de la madre que enseña a sus hijos las primeras oraciones, tampoco se debería titubear en afirmar la eclesia-

${ }^{30}$ Bosch, V., Santificar el mundo desde dentro. Curso de espiritualidad laical, Madrid: BAC, 2017, 111.

${ }^{31}$ Bosch, V., «Azione ecclesiale e impegno nel mondo dei fedeli laici: una insidiosa distinzione», Annales theologici 26 (2012) 133. 
lidad del trabajo realizado por un obrero o un profesional que busca santificarse con su actividad, sirviendo a los demás, mejorando el mundo y alabando a Dios. Cuando se ejerce cualquier profesión con perfección humana y sobrenatural (caridad e intención) se está purificando el correspondiente ámbito de esas realidades terrenas y están siendo conducidas a Dios. $\mathrm{Y}$ en esto consiste -no lo olvidemos- una de las dos caras de la moneda de la misión de la Iglesia. En el origen de una falta de reconocimiento del carácter eclesial del compromiso del laico en el mundo se puede detectar el prejuicio clerical del pensar que el cristiano es más cristiano en la medida en que se involucra en funciones y tareas eclesiásticas. Lo había denunciado hace medio siglo san Josemaría, promotor de una espiritualidad laical basada en la santificación del trabajo profesional: «Hay que rechazar el prejuicio de que los fieles corrientes no pueden hacer más que limitarse a ayudar al clero, en apostolados eclesiásticos. [...] El modo específico de contribuir los laicos a la santidad y al apostolado de la Iglesia es la acción libre y responsable en el seno de las estructuras temporales» ${ }^{32}$. Y también lo ha evidenciado, recientemente, el Papa Francisco: «El clericalismo lleva a la funcionalización del laicado; tratándolo como "mandaderos", coarta las distintas iniciativas, esfuerzos y hasta me animo a decir, osadías necesarias para poder llevar la Buena Nueva del Evangelio a todos los ámbitos [...]. Muchas veces hemos caído en la tentación de pensar que el laico comprometido es aquel que trabaja en las obras de la Iglesia y/o en las cosas de la parroquia o de la diócesis y poco hemos reflexionado cómo acompañar a un bautizado en su vida pública y cotidiana; cómo él, en su quehacer cotidiano, con las responsabilidades que tiene se compromete como cristiano en la vida pública. Sin darnos cuenta, hemos generado una élite laical creyendo que son laicos comprometidos sólo aquellos que trabajan en cosas "de los curas" y hemos olvidado, descuidado al creyente que muchas veces quema su esperanza en la lucha cotidiana por vivir la fe» ${ }^{33}$.

En conclusión, el trabajo santificado de los laicos en medio del mundo, que bajo el influjo de la gracia promueven la justicia y el bien común en su deseo de llevar las cosas creadas hacia Dios, tiene por su misma naturaleza carácter eclesial, sin ser una actividad eclesiástica. Si se afirma que es misión de la Iglesia «la restauración de todo el orden temporal» (Apostolicam actuositatem,

32 SAn Josemaría EscrivÁ, Conversaciones con Mons. Escrivá de Balaguer, nn. 34/a y 59/b, 243 y 303.

33 Francisco, Carta al Card. Ouellet, Presidente de la Pontificia Comisión para América Latina, 19-III2016. 
5), se debe reconocer también: 1) el carácter eclesial del trabajo santificado que los fieles laicos llevan a cabo desde la entraña del mundo; y 2) que esa función o tarea responde a una misión a la que muchos están llamados, constituyendo, por tanto, una vocación divina.

\section{VOCACIÓN Y SENTIDO DE MISIÓN DE LOS FIELES LAICOS}

\section{a) La formación de los fieles laicos}

Acoger la invitación divina a introducirnos en el flujo de amor intratrinitario, al que son convocados todos los hombres, colma de sentido la existencia humana, mientras que desestimarla podría constituir un menosprecio a Dios y a la propia dignidad. Señalaba con razón Mouroux que el hombre está marcado por una vocación: «un ser espiritual no es otra cosa que el término -personal y consciente- de una voluntad personal de Dios. [...] Su más profunda realidad es ser llamado, es decir, puesto en la existencia, no sólo para mantenerse en ella, sino para perfeccionarse por sí mismo» ${ }^{34}$. En otras palabras, el hombre descubre la verdad sobre sí mismo al discernir el proyecto vital que Dios tiene sobre él. Y este discernimiento no se logra intentando penetrar en la mente divina, cosa imposible para la criatura: es la misma providencia divina quien va guiando la libertad de la persona en el descubrimiento y realización de ese plan. Por eso, la vocación no se elige, sino que se descubre y se acepta: la vocación es el para qué de la vida, aquello para lo que cada persona ha sido creada. Se entiende, entonces, que el designio divino afecte a cada hombre en sus concretas condiciones de vida; es decir, en los talentos recibidos, las aficiones y tendencias, la posición social y cultural, la salud, etc. Y como la vocación es siempre «para algo», la variedad de situaciones y condiciones de vida manifiesta que cada cristiano tiene una misión o tarea que debe realizar.

Por eso, uno de los grandes desafíos pastorales que tiene ante sí la Iglesia en nuestros días es lograr concienciar a esa multitud de fieles laicos, cristianos «de a pie», de haber recibido una vocación divina y de estar llamados a santificarse en su ambiente profesional, purificando con su actuar cristiano las realidades terrenas y conduciendo, así, el mundo hacia Dios. La potencia evangelizadora de los laicos está todavía por descubrir y hacer explotar. Los fieles laicos, por estar colocados en la entraña del mundo para actuar «desde

\footnotetext{
${ }^{34}$ Mouroux, J., Sentido cristiano del hombre, Madrid: Palabra, 2001.
} 
dentro, a modo de fermento» (Lumen gentium 31), no pueden prescindir, en sus relaciones con Dios, de sus obligaciones de estado familiar y laboral, ni de su inserción en los ámbitos cultural, socio-político, económico, etc. Todo eso constituye parte importante de su vida espiritual, de su relación con Cristo, marcándola y condicionándola profundamente. Se podría afirmar que la vida espiritual del laico se desarrolla entre dos coordenadas o componentes irrenunciables: la coordenada vertical de comunión con Dios, de unión a Cristo por la fe y la caridad; y la horizontal, de inserción en las realidades temporales y participación en las actividades terrenas. A estas dos coordenadas o elementos de la existencia cristiana del laico dedicaremos nuestras próximas reflexiones: la primera -la vertical-, a continuación, y la segunda -la horizontalen el siguiente apartado.

En primer lugar, y a coste de parecer obvio, no hay que olvidar que ser laico es un modo de ser cristiano: un bautizado que ha sido llamado a encontrar a Dios en, y a través de, su vida ordinaria -familia, trabajo, relaciones sociales-, asumiendo toda su existencia con el sentido y los valores que otorga la fe cristiana. En otras palabras, el laico es ante todo un fiel cristiano, con una vida espiritual cristiana cuya sustancia precede todas sus modalidades de realización. Presupuestos básicos de su comunión con Dios son las condiciones espirituales del cristiano y la autocomunicación libre y gratuita de Dios. Lo que Dios comunica es su propia santidad para que el cristiano, haciendo uso de su libertad, la manifieste en las condiciones personales e históricas en la que es colocado por la Providencia divina. Toda existencia cristiana está marcado por unas dimensiones constitutivas, que mencionaremos muy brevemente: es una vida «trinitaria y filial» (Cristo nos ha hecho conocer al Padre, y la acción del Espíritu Santo conduce al cristiano a sentirse -y vivir como- hijo de Dios); es una vida «cristocéntrica» (la santidad consiste en la plena identificación con Cristo, que incluye la participación en su misión); es una vida «pneumatológica» (el Espíritu Santo es el artista que esculpe en el cristiano la imagen de Cristo); es una vida «eclesial», litúrgica, apostólica, mariana (Cristo se une al cristiano en la Iglesia, y como una madre le alimenta con la Palabra y los sacramentos); es una vida «histórica», encarnada (la intimidad con Dios no requiere un aislamiento de la realidad, no es un espiritualismo sin mundo); y, por último, es una vida «escatológica», en tensión hacia una plenitud que sólo se alcanzará en el más allá.

Sin perder de vista estos elementos constitutivos de la vida cristiana, aludimos ahora al desarrollo de la vida espiritual, que fundamentalmente consis- 
te en: el crecimiento en las virtudes teologales, que tienen por objeto directo «creer a y en», «esperar en» y «amar a» Dios; el desarrollo de las virtudes humanas y de la humildad; el combate espiritual o lucha interior contra las tendencias desordenadas (mortificación y esfuerzo por percibir habitualmente la cercanía de Dios); y la vida de oración, que es medio indispensable para crecer en nuestra unión vital con Dios y no aparta del compromiso en el mundo y en la historia (es más, la contemplación ha de desembocar siempre en la acción). Oración y obras se funden en una sola realidad: las obras de trabajo, de vida familiar y social son palabras del diálogo con Dios. En efecto, cuando las obras del cristiano imitan el obrar divino -es decir, se hacen con inteligencia y amor, con perfección humana y caridad- esas obras se convierten en oración, en diálogo con Dios.

Además, en la vida espiritual de los fieles laicos es posible detectar algunos rasgos característicos, que aquí sólo enunciaremos ${ }^{35}$ : una particular experiencia cristiana de lo humano y una especial sensibilidad hacia lo humano (podríamos hablar de una «espiritualidad de la encarnación» en la que lo teologal fecunda las situaciones y tareas de la concreta existencia humana); una amor teologal al mundo (aprecio y estima de las realidades terrenas, de sus valores y destino); una valoración positiva de la vida ordinaria (capacidad de trascender lo normal de cada día, otorgando a esas tareas la grandeza del amor); competencia profesional y sentido de responsabilidad; conciencia de la ordenación a Dios de las realidades terrenas (un sentido teologal de las cosas que, al mismo tiempo, respete su naturaleza y leyes propias); y, finalmente, un acentuado sentido de la libertad personal (necesaria para decidir opciones profesionales, políticas, económicas, según la propia conciencia informada por la fe, y sin disolver la responsabilidad en la comunidad).

Estos presupuestos de vida cristiana de los fieles laicos requieren la presencia y acción de la Iglesia -como ya señalamos- y, especialmente, del servicio de los ministros sagrados. En concreto, la responsabilidad de la formación de los fieles laicos corresponde en cada diócesis al obispo con la colaboración de su presbiterio: «la formación de los fieles laicos se ha de colocar entre las prioridades de la diócesis y se ha de incluir en los programas de acción pastoral de modo que todos los esfuerzos de la comunidad (sacerdotes, laicos y religiosos) concurran a este fin ${ }^{36}$. Y el texto de Christifideles laici señala inmediatamente que la prio-

${ }^{35}$ Cfr. Bosch, V., Santificar el mundo desde dentro, 176-180.

${ }^{36}$ San Juan Pablo II, ex. ap. Christifideles laici, n. 57. 
ridad de esa formación consiste en ayudar a que los fieles laicos descubran y vivan su propia vocación y misión ${ }^{37}$. Se trata de un servicio que el sacerdocio ministerial ofrece al sacerdocio bautismal de los laicos, con el fin de promover en ellos el pleno ejercicio de su misión en el Pueblo de Dios. Importa destacar que «la actuación de este servicio de promoción exige que los ministros sagrados comprendan a fondo la importancia, las características propias y también las dificultades de la misión de los laicos. Con otras palabras, que hayan asimilado tanto el aspecto sustantivo (identidad cristiana) como adjetivo (modalización laical) de su condición y de su tarea, de manera que su presencia cristiana en el mundo sea entendida en toda su profundidad, valor y alcance teológico y eclesial: como auténtico don y misión en la Iglesia» ${ }^{38}$. Ésta es una función clave de obispos y presbíteros, que difícilmente podrán transmitir a los fieles laicos la dignidad de su vocación y misión peculiar (santificar el mundo desde dentro) si los mismos ministros no están firmemente convencidos de ello: mientras haya sacerdotes con actitudes paternalistas que consideran a los laicos su longa manus en funciones eclesiásticas (monaguillos a vita), la potencia evangelizadora de los laicos continuará sin explotar. El protagonismo de los laicos seguirá siendo una caricatura: la de un ejército de menores siempre necesitados de tutela, y a quienes, desde lo alto, impartir órdenes sobre su cometido.

En el reconocimiento y promoción de la auténtica vocación de los laicos y de su misión peculiar en la Iglesia juegan un papel importante la catequesis y el acompañamiento espiritual. Respecto a la catequesis, las Iglesias particulares y comunidades cristianas deberían renovar sus esfuerzos: transmitir a los fieles laicos el sentido vocacional de su existencia requiere una oferta de formación que sea atractiva y eficaz (cursos de teología para laicos, conferencias, debates, etc. en locales acogedores, limpios, caldeados). Además, como todo cristiano, también el laico necesita ser acompañado para vivir su vocación y misión. Es verdad que la comunidad constituye siempre un importante apoyo en el camino, pero no basta. Se necesita también el consejo personalizado, la sugerencia práctica, una luz capaz de alumbrar en las particulares circunstancias de cada persona. La modalidad de este acompañamiento es variada: desde la confesión frecuente con un mismo sacerdote si es conveniente, hasta las

${ }^{37}$ Ibid., n. 58: «La formación de los fieles laicos tiene como objetivo fundamental el descubrimiento cada vez más claro de la propia vocación y la disponibilidad siempre mayor para vivirla en el cumplimiento de la propia misión».

${ }^{38}$ Río, P., «I fedeli laici a 50 anni del Concilio Vaticano II», Annales theologici 31 (2017) 116. 
conversaciones de dirección espiritual que -en un clima de fraternidad y libertad- se pueden tener con una persona experta (sacerdote, religioso o laico ${ }^{39}$. En definitiva, la función de los pastores en la promoción de la vocación y misión de los fieles laicos se puede resumir en ayudarles a vivir su fe en las condiciones ordinarias de su existencia, y en fomentar su compromiso en una efectiva evangelización y transformación de la sociedad.

\section{b) Evangelización y transformación de la sociedad}

El dinamismo «de salida» que el Papa Francisco quiere provocar en una Iglesia misionera requiere un mayor compromiso de los fieles laicos en lograr que los valores cristianos penetren el mundo social, político y económico. Confesión de la fe y compromiso social van de la mano ${ }^{40}$. Y la primera forma de evangelización es el testimonio cristiano, entendido como «la coherencia de la vida ("ejemplo") acompañada, siempre que sea posible, de las palabras que explican la propia conducta en relación con los valores éticos y la vida de fe» ${ }^{41}$. Esta responsabilidad misionera o apostólica incluye la promoción humana de las personas, con una búsqueda y práctica concreta de la justicia y de la caridad en las normales circunstancias en las que cada uno se encuentra, en particular «en su ambiente familiar y laboral, pues el mundo se transforma a partir de las relaciones con los que tenemos más cerca, informadas por la caridad de Cristo, y por el propio trabajo transformado por el amor: es decir, traducido en cumplimiento competente y responsable de los propios deberes profesionales $[\ldots] \gg^{42}$.

Estamos hablando de caridad y conviene detenernos brevemente para considerarla como raíz de la transformación del mundo, porque inicialmente lo es de la persona. La caridad es la clave cristiana de toda ética, es el nuevo obrar que corresponde al nuevo ser de quien ha sido injertado en Cristo. Con

39 CONGREGACIÓN PARA EL CLERO, El sacerdote confesor y director espiritual, ministro de la misericordia divina (9-III-2011), n. 65: «Aunque haya prevalecido la dirección espiritual impartida por monjes y por sacerdotes ministros [...] hay también fieles laicos bien formados -hombres y mujeresque realizan este servicio de consejo en el camino de la santidad».

40 FRANCISCO, ex. ap. Evangelii gaudium, n. 178: «La aceptación del primer anuncio, que invita a dejarse amar por Dios y a amarlo con el amor que Él mismo nos comunica, provoca en la vida de la persona y en sus acciones una primera y fundamental reacción: desear, buscar y cuidar el bien de los demás».

41 Pellitero, R., Laicos en la nueva evangelización, Madrid: Rialp, 2013, 144.

${ }^{42}$ Río, P., «I fedeli laici a 50 anni del Concilio Vaticano II», 121. 
el bautismo el cristiano ha sido re-creado en Jesucristo, es una nueva creatura que participa de la vida del Espíritu que el Resucitado ha enviado a los suyos (cfr. Rom 8,9-11). La vocación cristiana es consecuencia de haber sido hechos «hombres nuevos» en el Verbo Encarnado y con la efusión del Espíritu Santo. Es importante saber percibir la belleza del don de ser «partícipes de la naturaleza divina» (2 Pe 1,4), ser conscientes de que el misterio de la gracia consiste en una auténtica «deificación» del alma, expresión que arrancaba los aplausos de los labriegos y pescadores de Hipona en los sermones de san Agustín. La caridad -don por el que amamos a Dios sobre todas las cosas- radica en la voluntad, que es la potencia encargada de mover hacia el fin a las demás facultades del hombre, otorgando una dinámica de unidad al propio ser y a todo su actuar: «la caridad, como amor a Dios y en Dios, trasvasa a cada acción de la persona la trascendencia del fin, hace presente allí la intención suprema se someterse voluntariamente a Dios y a su gloria $\gg^{43}$. Aquí estamos recordando la mencionada coordinada vertical de la vida espiritual: la unión con Cristo por la fe y la caridad. Sin esta premisa no es posible santificar nada, ni llevar el mundo hacia Dios.

No es superfluo subrayar que la dimensión mística de la vida cristiana no aleja de la vida concreta: la verdadera contemplación desemboca en la acción, convierte lo ordinario en extraordinario mediante el amor. Efectivamente, la progresiva identificación con Cristo -sustancia y meta de toda vida espiritualrequiere asumir y vivir la actitud y práctica de su amor misericordioso hacia todos los hombres. El Mandatum novum de amarse «como yo os he amado» (Jn 13,34) no sonó en los oídos de los Apóstoles como una formulación abstracta, sino que hacía traer a su mente situaciones concretas en los que Jesús manifestó con obras su amor a todos. Con razón señala Pellitero que la caridad «es criterio definitivo de la autenticidad de la acción eclesial, y, también [...] el principal impulso y el principal fruto de la misión laical» ${ }^{44}$. La caridad está colocada en el centro mismo de la Doctrina social de la Iglesia, porque los cristianos están llamados a trasformar el mundo y la historia desde Cristo mediante $\ll$ la fe que actúa por la caridad» $(\mathrm{Gal} 5,6)$.

Vistas así las cosas, la acción de los fieles laicos en el mundo constituye un mar sin orillas, una vasta gama de posibilidades, un panorama enaltecedor de la

${ }^{43}$ ARANDA, A., La lógica de la unidad de vida. Identidad cristiana en una sociedad pluralista, Eunsa: Pamplona, 2000, 123.

44 Pellitero, R., Laicos en la nueva evangelización, 163. 
propia vocación, atractivo y capaz de dar sentido a la propia existencia. El Sínodo del 2012 sobre la nueva evangelización insistió en su tres documentos $-\mathrm{Li}$ neamenta, Instrumentum laboris y Mensaje al Pueblo de Dios- en la necesidad de comprender mejor aquellos ámbitos que más condicionan la compleja situación de nuestros tiempos. Para referirse a estos ámbitos se acuñó el término de «escenarios» y se describieron seis: cultura, fenómeno migratorio, economía, política, pensamiento científico y comunicación. Estos ámbitos o escenarios «forman parte del amplio panorama de las realidades seculares, y tienen como principales protagonistas - la mayoría de las veces, los únicos- a los laicos. Son ellos los que han de evangelizar en esos escenarios $y$ esos escenarios: las personas y las realidades» ${ }^{45}$. La misión eclesial de evangelizar la cultura y la vida social conduce a los laicos a santificar todas las realidades terrenas: los escenarios mencionados y muchos otros, como las artes, el deporte y el tiempo libre. Todo es susceptible de ser llevado hacia Dios, de ser purificado de la corrupción del pecado, y por tanto, de ser medio de santificación propia y de los demás: «Desde dentro del mundo, es decir desde la dinámica originaria de la sociedad civil, el laico colabora con el acto creador de Dios Padre, con el acto redentor de Cristo, que libera al mundo del pecado y con el acto santificador propio del Espíritu Santo, al responder a su vocación a la santidad en su circunstancias históricas concretas» ${ }^{46}$. Y aquí remitimos a las ideas-madre sobre el trabajo santificante y santificador, presentes en nuestra introducción. Pero tener una visión del trabajo como perfeccionamiento de la Creación y medio para dar gloria a Dios requiere una particular conciencia de que esta misión fue ya iniciada por Cristo. Nosotros somos meros colaboradores en algo que puso en marcha Cristo, Señor del cosmos y de la historia. La Creación hay que entenderla totalmente en relación con Cristo: en su origen, en su ser y en su destino último. La Redención de Cristo es como la revelación del sentido definitivo de la historia y el inicio de la Creación escatológica. La Pascua, que sanciona la victoria de Cristo, marca una fractura en la historia entre el tiempo anterior a Cristo, un mundo de pecado y de tinieblas, y el tiempo posterior, un mundo redimido y en vías de ser glorificado. En otras palabras, la Pascua representa el ingreso de la historia en la escatología. Conviene, ciertamente, que los fieles laicos tengan presente la

45 Bosch, V., Santificar el mundo desde dentro, 201. Para una visón panorámica de esos escenarios, cfr. 201-211.

${ }^{46}$ Pellitero, R., «La identidad de los cristianos laicos a la luz del Concilio Vaticano II», Scripta Theologica 47 (2015) 503. 
gran perspectiva de la recapitulación de todas las cosas en Cristo (cfr. Ef 1,10). Esta cristología cósmica está muy bien representada en algunos mosaicos bizantinos en los que el Kyrios asciende al cielo desde la cumbre de todo lo creado, representado por la fauna y la flora.

En todo este gran proyecto de salvación escondido en Dios desde la eternidad, revelado en Cristo y desarrollado en la Iglesia hasta su cumplimiento final, el bautizado es protagonista y responsable -con toda la Iglesia- de su realización. Es decir, toda vocación -y, por tanto, también la laical- es sujeto activo en la bistoria salutis. Cristo Resucitado representa la anticipación del futuro que está todavía por construir. Es decir, la victoria de Cristo ya se ha dado, pero sólo en la parusía será visiblemente completa. Mientras tanto, este tiempo intermedio es tiempo de lucha para llevar a cabo el plan de Dios, y ningún bautizado puede retraerse de este combate. Existe en la Iglesia, por tanto, una profunda relación entre vocación cristiana y la realización de la historia de la salvación. Los bautizados, cada uno de los «llamados» son personas «teológicas»: con ellas y mediante ellas se desarrolla y actúa la historia salutis en el seno de una humanidad que camina hacia los cielos nuevos y la nueva tierra.

Sólo un cuadro cristológico amplio, una cristología vocacional, es capaz de revitalizar la teoría y la praxis de la llamada al seguimiento de Cristo y su discernimiento. Y, más en concreto, de dar alma a una pedagogía que confiera sentido vocacional a la condición laical. No es el laico un cristiano de segunda categoría, alguien que por no tener vocación abdica de pretensiones de santidad, no es un individuo más dentro de un colectivo sin particular misión o tarea. Nada más lejos de la realidad. Tiene vocación, está llamado a ser santo y se le ha confiado una misión bien atractiva y comprometedora: renovar el mundo con Cristo, ser su partner en la empresa de liberar la Creación de la esclavitud de la corrupción.

\section{Conclusiones}

El recorrido realizado ha querido poner en relación el concepto de vocación con la doctrina de la Iglesia sobre la condición laical de la mayoría de sus fieles, que normalmente consuman sus energías, talentos y días en un trabajo profesional. Esa actividad, además de producir una transformación en el mundo, transforma también a quien lo realiza, perfeccionándolo humana y sobrenaturalmente. El trabajo se constituye así en medio de santificación personal, del mundo y de los demás. Dios, en su Providencia, cuenta con el trabajo de 
los hombres para renovar el orden temporal y conducir todo hacia su fin. En el desarrollo de estas ideas no necesariamente se llegan a conclusiones novedosas. En todo caso, me limitaré a subrayar aquellos puntos que me parecen más relevantes para una pastoral y pedagogía de la vocación laical.

a) La vocación es siempre un misterio de la libérrima voluntad divina, que asigna a cada alma un papel en su plan salvador y redentor. Jesús sale al encuentro de cada hombre y mujer y, como con Juan y Andrés, les invita a «un camino interior y a una disponibilidad de ponerse concretamente en movimiento, sin saber bien a dónde esto les llevará. [...] Gracias a la valentía de ir y ver, los discípulos experimentarán la amistad fiel de Cristo y podrán vivir diariamente con Él, dejarse interrogar e inspirar por sus palabras, dejarse impresionar y conmover por sus gestos» ${ }^{47}$.

b) La vocación bautismal a la unión con Dios se declina y concreta personalmente tras un discernimiento en diálogo con el Señor y con la propia bistoria y características personales. En la vocación laical al seguimiento de Cristo en el ámbito secular de las encrucijadas del mundo, tal concreción puede declinarse como simple determinación de la vocación cristiana, o como vocación «peculiarespecífica» dentro de una institución eclesial, que incluso podría implicar -aunque no necesariamente- compromiso de celibato apostólico. En este último caso, importa subrayar que el celibato no disminuye lo más mínimo su condición plenamente secular: tales laicos no son «consagrados» camuflados.

c) Si la misión de la Iglesia consiste, junto con la salvación de las almas, en la santificación del mundo, no es posible seguir ignorando el carácter eclesial del trabajo santificado y santificador de los laicos en medio del mundo. «Allí están llamados por Dios», esto les «corresponde por vocación», dijo con fuerza el Concilio, y san Juan Pablo II insistió en que «la índole secular del fiel laico no debe ser definida solamente en sentido sociológico, sino sobre todo en sentido teológico» ${ }^{48}$.

d) Vivir la existencia cristiana laical con sentido vocacional requiere el servicio del ministerio sacerdotal y el acompañamiento espiritual. Por eso, resulta indispensable que los pastores conozcan y promuevan la dignidad de la vocación y misión de los laicos, y sean conscientes de las dificultades que encuentran en su concreto ámbito de influjo (familiar, laboral, social).

\footnotetext{
47 SínODO DE LOS OBISPOS, Los jóvenes, la fe y el discernimiento vocacional, 10.

48 San Juan Pablo II, ex. ap. Christifideles laici, n. 15.
} 
e) La pastoral vocacional debe presentar en toda su grandeza la existencia cristiana laical, ofrecer una visión amplia que hunda sus raíces en el Verbo Encarnado, paradigma de toda secularidad. Recibir la vocación de seguir a Cristo en medio del mundo constituye una tarea enaltecedora que otorga sentido y sustancia a la vida: restaurar el mundo con Cristo. «Cada joven puede descubrir en la vida de María el estilo de la escucha, la valentía de la fe, la profundidad del discernimiento y la dedicación al servicio [...]. Ella también está llamada a vivir el éxodo de sí misma y de su proyectos, aprendiendo a entregarse y a confiar» ${ }^{49}$.

49 SíNODO DE LOS OBISPOS, Los jóvenes, la fe y el discernimiento vocacional, 64. 


\section{Bibliografía}

ÁLVAREZ DE LAS ASTURIAS, N., «Teología y pastoral de la vocación en el contexto actual», Scripta Theologica 49 (2017) 595-617.

ARAnda, A., «El cristiano, Alter Christus, ipse Christus en el pensamiento del beato Josemaría Escrivá de Balaguer», en BELDA, B., EscUDERO, J., ILLANES, J. L. y O'Callaghan, P. (eds.), Santidad y mundo. Actas del Simposio teológico de estudio en torno a las enseñanzas del beato fosemaría Escrivá, Pamplona: Eunsa, 1996, 129-187.

ARANDA, A., La lógica de la unidad de vida. Identidad cristiana en una sociedad pluralista, Pamplona: Eunsa, 2000.

Beato Pablo VI, Discurso a los representantes de los institutos seculares sacerdotales y laicales, 2-II-1972.

Bosch, V., «Azione ecclesiale e impegno nel mondo dei fedeli laici: una insidiosa distinzione», Annales theologici 26 (2012) 127-136.

Bosch, V., Santificar el mundo desde dentro. Curso de espiritualidad laical, Madrid: BAC, 2017.

Bosch, V., «Vocación», en Izquierdo, C. (dir.), Burgrgraf, J., Arocena, F. M. y Brugarolas, M., Diccionario de Teología, 3 ed. Pamplona: Eunsa, 2014, 1057-1067.

Concilio Vaticano II, decr. Apostolicam actuositatem (18-XI-1965).

Concilio Vaticano II, const. Gaudium et spes (7-XII-1965).

Concilio VatiCANo II, const. Lumen gentium (21-XI-1964).

CONGREGACIÓN PARA EL CLERO, El sacerdote confesor y director espiritual, ministro de la misericordia divina (9-III-2011).

Francisco, Carta al Card. Ouellet, Presidente de la Pontificia Comisión para América Latina, 19-III-2016.

FrancisCo, ex. ap. Evangelii gaudium (24-XI-2013).

GOYRET, P., «The Decree Apostolicam actuositatem, Highlights of Vatican II's Teaching on Laity», Annales theologici 31 (2017) 87-102.

LÉSAGE, S., «Vocation, I. Écriture sainte», DSp 16 (1994) 1082-1092.

Miralles, A., «La vocación de los cristianos: reflexión teológica sobre los principales textos neotestamentarios», en VILLAR, J. R. (ed.), Communio et sacramentum, Pamplona: Eunsa, 2003, 345-366.

Mouroux, J., Sentido cristiano del hombre, Madrid: Palabra, 2001.

OCÁRIZ, F., «Vocación a la santidad en Cristo y en la Iglesia», en BELDA, M., Escudero, J., Illanes, J. L. y O'Callaghan, P. (ed.), Santidad y mundo, 
Actas del Simposio teológico de estudio en torno a las enseñanzas del beato fosemaría Escrivá, Pamplona: Eunsa, 1996, 35-54.

Pellitero, R., «La identidad de los cristianos laicos a la luz del Concilio Vaticano II», Scripta Theologica 47 (2015) 483-503.

Pellitero, R., Laicos en la nueva evangelización, Madrid: Rialp, 2013.

Río, P., «I fedeli laici a 50 anni del Concilio Vaticano II», Annales theologici 31 (2017) 103-122.

RocchetTa, C., «Forti e costanti ispirazioni di fede. Teologia della vocazione. Valutazione e fondamento cristologico», Seminarium 36 (1996) 35-56.

RocchetтA, C., «Quale teologia al centro dell'animazione e della pastorale vocazionale?», Vocazioni 23 (2006/4) 4-22.

San Agustín, Confesiones I, 8 ed. Madrid: BAC, 1991.

San Josemaría Escrivá, Conversaciones con Mons. Escrivá de Balaguer, ed. crítico-histórica preparada por Illanes, J. L. y MÉNDIZ, A., Madrid: Rialp, 2012.

San Juan Pablo II, ex. ap. Christifideles laici (30-XII-1988).

SAN JuAN PABlo II, enc. Laborem exercens (14-IX-1981).

San Juan Pablo II, ex. ap. Reconciliatio et paenitentia (2-XII-1984).

SAN JuAn PABLO II, enc. Redemptor hominis (4-III-1979).

SíNODO DE LOS OBISPOS, Los jóvenes, la fe y el discernimiento vocacional. Documento preparatorio. Introducción, Città del Vaticano: Libreria Editrice Vaticana, 2017. 